to the recorders for examination and classification, and then returned to the editor before going to the printers; and finally there is the proof reading involved in dealing with approximately fifteen thousand titles in many different languages.

The present volume follows the same general plan as previous ones for a number of decades and retains a somewhat artificial grouping of the animal kingdom. Thus the section Vermes includes such diverse groups as Platyhelminthes, Nemertinea, Mesozoa, Nemathelminthes, Annelida and a number of smaller classes. It might be an advantage to subdivide this section in accordance with some generally accepted scheme of modern classification, at least for the benefit of subscribers to separate sections.

The value of the "Zoological Record" to all zoologists increases with each succeeding volume, as it furnishes a more-or-less complete bibliography of the subject since its foundation in 1864. Its usefulness has been enhanced in recent years by the adoption of a general plan whereby some indication is given of the contents of each paper which are not always obvious from the title.

The list of titles, arranged alphabetically according to the name of author, is followed by a subject index in which the titles are grouped according to the particular aspects dealt with in the paper, and finally by a systematic index, in which all the species mentioned are listed according to a generally accepted scheme of classification.

The "Record" gives some indication of the work in various branches of systematic zoology in the number of titles in each of the eighteen sections into which it is subdivided. Volume 88 includes the following : comprehensive zoology, 437; Protozoa, 1,126 ; Porifera, 41 ; Coelenterata, 274 ; Echinoderma, 344 ; Vermes, 1,011; Brachiopoda, 211; Bryozoa (Polyzor), 56; Mollusca, 729 ; Crustacea, 556 ; Trilobita, 78 ; Arachnida, 666 ; Insecta,'335 ; Protochordata, 51 ; Pisces, 1,088; Amphibia and Reptilia, 1,233 ; Aves, 2,031 ; and Mammalia, 1,635. In addition, 1,813 new generic and subgeneric names were recorded in 1951. It will be seen that, as usual, the greatest number of papers deals with insects, birds and mammals occupying the next two places.

Certainly, no taxonomic zoologist can afford to be without this publication, and specialists in all branches of zoology will find it invaluable in dealing with the ever-increasing amount of literature on the subject. The title-page of the "Record" carries the words "Explorate solum : sic fit via certior ultra"a very apt quotation, for the ground is fully explored by the editor and recorders, thus making the way ahead more certain.

Edward Hindue

\section{PHYSICO-CHEMICAL OPTICS}

An Advanced Treatise on Physical Chemistry By Prof. J. R. Partington. Vol. 4 : Physico-Chemical Optics. Pp. $x l+668$. (London: Longmans, Green and Co., Ltd., 1953.) 80s. net.

$\mathrm{T}$ HIS fourth volume of the monumental "Advanced Treatise on Physical Chemistry", like the earlier volumes (see Nature, 167, 740 (1951); $169,46(1952) ; 171,853(1953)$ ), fills the reader with astonishment and admiration for the encyclopædic knowledge, historical sense, attention to detail and mathematical powers shown by the author.
Prof. J. R. Partington has evidently collected references on physico-chemical subjects over many years. He has read these references, noted their essential points and kept them in remembrance. $\mathrm{He}$ has a strong feeling for the great pioneers of the nineteenth century, and his extensive reading of earlier scientific work enables him to do them full justice, and to correct with meticulous accuracy the misconceptions and omissions of text-book writers.

Being based on collections, the book has a museumlike flavour; a museum of old-fashioned type rather than those modern ones with a few well-selected exhibits under brilliant illumination. Each worker's contribution is treated as an object to be found shelfroom. Pride of place is given to those classical subjects which can be developed with rigorous elegance from first principles. More than 130 pages are devoted to Maxwell's electromagnetic theory of light, which is followed from its beginnings to its applications to complex matters of refraction, wave-surfaces in crystals, etc. Other extensive mathematical treatments are of light scattering (50 pages), polarization of light (80 pages), dispersion ( 16 pages) and diffraction (15 pages). These treatments are clearly presented and, because of the author's desire to bring out the contributions of individuals, are necessarily prolonged. A valuable feature is the attention directed to the varying use of symbols by different authors. The Kerr, Faraday, Cotton and CottonMouton effects are discussed more fully than in any other text-book. The chemist will be grateful for this storehouse of theory, much of which is not readily accessible. The emphasis, however, is always on the mathematical and physical side, and the chemical aspects are somewhat slightly touched on. As an example, fifty pages of highly physical theory on the scattering of light are accompanied by two pages of its applications to solutions of macro-molecules, and three pages to the Raman effect. The same physical bias is present in the treatments of artificially produced double refraction, of the interference of light, and of dichroism, while the several pages devoted to Airy's spirals and radiation pressure seem to be pure physies.

The secondary objects exhibited in the book are the numerous empirical relationships between physical properties which have been put forward by lesser scientists. The author has aimed at completeness in his record, increasing its value for reference, while diminishing it for student reading. In this field he is less insistent on mathematics. About Eykman's equation he says : "although it does not yet seem to have been favoured by a theoretical deduction, unlike so many formulæe which are useless for practical applications, it is one which deserves to be kept in mind".

The least satisfying part of the book lies in its accounts of instruments and experimental methods. All the ways of measuring interference of light, refractive index, etc., are given with little indication of which a newcomer to research should choose. Only a superhuman scientist, of course, could combine Prof. Partington's range of knowledge in all branches of physical chemistry with an equal skill in all modern experimental techniques. The book will find a unique place in every scientific library and will be constantly consulted both by students and by research workers; all physical chemists who can afford a copy should obtain one.

E. J. BowEN 